\title{
Comunicação em saúde: percepção dos usuários em um serviço de oncologia
}

\author{
Health communication: perception of users in an oncology service
}

\author{
Larissa Sorayane Bezerra Soaresa, Larissa Polejack ${ }^{b}$ \\ a Psicóloga. Psico-oncologista pelo Programa de Residência Multiprofissional em Saúde - Atenção Oncológica do HUB/UnB, Brasília, Brasil. \\ Psicóloga na Empresa Brasileira de Serviços Hospitalares - Ebserh. \\ b Psicóloga. Doutora em Processos de Desenvolvimento Humano e Saúde pela Universidade de Brasília. Bolsista CAPES de Pós-doutorado em Saúde Pública pela \\ Tulane University/EUA. Professora Adjunta do Departamento de Psicologia Clínica, Instituto de Psicologia, Universidade de Brasília, Brasília, Brasil.
}

RESUMO

Objetivo: Analisar a percepção da pessoa com câncer, em tratamento, sobre a comunicação em saúde, identificando suas preferências sobre a transmissão de informações relacionadas ao adoecimento e ao tratamento, para o próprio usuário e seus familiares, e as dificuldades relacionadas ao direito à informação e ao exercício da autonomia.

Materiais e Métodos: Optou-se pela realização de um estudo exploratório e descritivo, de abordagem qualitativa. Foi utilizada a técnica da linha do tempo juntamente com um roteiro de entrevista semiestruturada. As entrevistas foram transcritas e submetidas à análise de conteúdo segundo proposta de Bardin.

Resultados: Participaram do estudo dez sujeitos $(n=10)$. A maioria dos participantes $(n=8)$ destacaram querer receber informações sobre a doença. Contudo, não se sentem capazes de participar do processo de tomada de decisão sobre o tratamento $(n=9)$. A análise dos dados revelou ainda seis categorias temáticas: a importância de saber sobre a doença; acesso aos serviços de saúde; interesse em saber sobre a doença e participar do tratamento; participação da família no tratamento; entraves à comunicação e; postura do profissional como facilitador da comunicação em saúde.

Conclusão: A inclusão no processo de comunicação é esperada pela maioria dos usuários do presente estudo, o que propicia condições para o exercício da autonomia. Contudo, permanece o desafio de preparar melhor os profissionais de saúde para promover condições para os sujeitos desempenharem sua autonomia. Sugere-se a implantação dos princípios da Política Nacional de Humanização para o enfrentamento de tal obstáculo.

Palavras-chaves: comunicação em saúde; equipe interdisciplinar; autonomia pessoal; revelação da verdade.

ABSTRACT

Objective: To analyze the perception of the person with cancer, receiving treatment, on the health communication, identifying their preferences on the transmission of information related to illness and treatment, for the user himself and his family, and the possible barriers to access the right to information and to exercise autonomy.

Materials and Methods: Exploratory and descriptive study of qualitative approach. The technique used was the "Timeline" combined with a semi-structured interview guide. The interviews were transcribed and analyzed according to Bardin's Content Analysis Methodology.

Results: The study included ten participants $(n=10)$. Most participants $(n=8)$ highlighted that they wanted to receive information about the disease. However, they do not feel able to participate in the decision-making process on the treatment $(n=9)$. Data analysis also revealed six thematic categories: the importance of knowing about the disease; access to health services; interest in knowing about the disease and participating in treatment; family participation in treatment; barriers to communication and; health worker role as a facilitator of quality health communication.

Conclusion: The inclusion in the communication process is expected by most participants of this study, which provides conditions for exercising autonomy. However, the challenge remains to prepare health workers to play a facilitator role on this process. It is suggested to implement the principles of the National Humanization Policy for addressing this challenge.

Keywords: health communication; interdisciplinary team; personal autonomy; truth disclosure.

\section{Correspondência:}

LARISSA SORAYANE BEZERRA SOARES

AE 04 Lote L Bloco A/B Apto 1504

71070-014 Guará, DF, Brasil

E-mail: larissasorayane@gmail.com 


\section{INTRODUÇÃO}

A comunicação do diagnóstico de câncer apresenta uma tarefa desafiadora para os profissionais de saúde, em especial para os médicos, por serem os responsáveis legais em diagnosticar a doença e indicar as opções de tratamentos ${ }^{1,2}$. Na realidade, a revelação é extremamente perturbadora para todos os atores envolvidos com as repercussões da comunicação de uma doença oncológica e é um dos grandes desafios para o trabalho em equipe interdisciplinar. Em relação ao médico, a dificuldade advém dos efeitos que a revelação causa no ouvinte, com manifestações de atitudes e comportamentos de difícil manejo para o profissional. Assim, a comunicação do diagnóstico de câncer ao indivíduo desencadeia uma série de sentimentos e comportamentos, tais como medo, ansiedade e isolamento, que podem ser potencializados pela representação social da doença neoplásica como sentença de morte ${ }^{3}$. Quanto à família, muitas vezes, pode ocorrer o pacto de silêncio, em que solicitam para a equipe não contar a verdade ao enfermo, sob a justificativa de que seu ente é fraco e deve ser protegido ${ }^{4}$.

Nesse sentido, estudiosos ${ }^{5,6,7}$ consideram que a não revelação pode estar relacionada com as dificuldades dos médicos, que utilizam do argumento de "preservar" o doente como um artifício para proteger o profissional da sua impotência. Sob esses aspectos, quando não se comunica um diagnóstico de câncer a quem se está realmente protegendo?

Em contrapartida, o dever ético e legal do médico de transmitir a informação está normatizado, e ao ser desempenhado promove um caminho para o exercício da autonomia dos usuários nos serviços de saúde. O acesso à informação pode minimizar o sentimento de isolamento e colaborar para uma relação de cooperação entre médicousuário $^{8}$, a depender da maneira que tais informações são compartilhadas entre esta díade. No cenário nacional, existem algumas legislações e documentos técnicos que vão ao encontro da defesa do princípio da autonomia, entre elas: Código de Ética Médica; Política Nacional de Humanização da Atenção e Gestão do SUS; Lei orgânica de saúde; Resolução no 1.995/2012 do Conselho Federal de Medicina que dispõe sobre as diretivas antecipadas de vontade dos pacientes e; Carta dos Direitos dos Usuários da Saúde ${ }^{1,9,10,11,12}$.

A comunicação é um meio para expressar-nos no mundo, seja por meio do verbal ou não verbal, e constitui a base das relações interpessoais ${ }^{13}$. Na área da saúde, a comunicação tem um papel essencial no cuidado e na promoção de saúde. O processo de comunicação configura-se um dos elementos essenciais para a execução da Política Nacional de Humanização (PNH) nos serviços de saúde9 .
Porém, podem ocorrer entraves à emancipação da comunicação. Verifica-se como empecilho as influências/ consequências geradas pelo modelo biomédico, com a valorização da objetividade, do tecnicismo, do reducionismo, da especialização e da fragmentação do saber ${ }^{14}$. Assim, a herança gerada pelo paradigma biomédico, em especial para a prática clínica, levou a substituição do encontro entre sujeitos, pelo uso extensivo de tecnologias duras ${ }^{15}$. O emprego das tecnologias não pode ser restrito a utilização de equipamentos, ferramentas, instrumentos e insumos físicos no trabalho em saúde. Usar tecnologia em saúde é também produzir vínculo e acolhimento com o usuário ${ }^{16}$.

Apesar de o usuário possuir legalmente o direito de saber do diagnóstico, prognóstico e participar das decisões terapêuticas, pode ocorrer, na prática clínica, que essas informações não são transmitidas, sob os argumentos e amparados no princípio ético da beneficência e nãomaleficência. Contudo, as ações que demarcam a divisão entre a beneficência e o paternalismo são tênues, o que leva os profissionais, em alguns estudos ${ }^{17,18}$, a reduzi-los ao mesmo constructo.

Diante dos conflitos éticos que permeiam a prática profissional, voltar-se para a bioética pode facilitar o manejo dos dilemas e a tomada de decisão consciente, ao analisar os valores/princípios envolvidos no caso. Alguns estudos ${ }^{6,19,20,21,22,23}$ que visam analisar o direito à informação do diagnóstico, concluem como a beneficência é reduzida ao paternalismo. Porém, também é equivocada a compreensão da autonomia como a exigência para divulgar todas as informações sobre o câncer a todos os enfermos em todas as circunstâncias, ou seja, uma necessidade absoluta do indivíduo sem qualquer exceção. A divulgação verdadeira, sem uma análise prévia dos interesses e preferências do usuário, não é sinônimo de respeito à autonomia ${ }^{24}$. Nesse sentido, uma abordagem paternalista é tanto reter informações da pessoa com câncer, quanto ignorar os desejos e as necessidades dos mesmos.

Atitude e práticas de dizer a verdade sofrem modificações ao longo dos anos. Os agentes para esta mudança devem-se a fatores médicos, jurídicos, políticos e sociais entrelaçados, tais como a evolução dos códigos de éticas profissionais, regulamentação dos consentimentos informados obrigados por lei, evolução dos tratamentos oncológicos, oferta do programa de cuidados paliativos, ingresso da disciplina de bioética nas faculdades de medicina e veiculação do câncer na mídia $7,25,26$.

Porém, ainda são escassos no Brasil estudos que tenham como objetivo avaliar o desejo dos indivíduos de receber informações sobre a doença e participar das decisões 
terapêuticas e, também, se os mesmos desejam que a família seja informada e participe das escolhas e conduta durante o processo de adoecimento ${ }^{8}$. Diante dos dilemas vivenciados por todos os envolvidos na comunicação de um diagnóstico da doença neoplásica e do seu tratamento, apesar das várias legislações que respaldam o direito ao exercício da autonomia do usuário, o presente trabalho justifica-se por propiciar um lugar de protagonista à pessoa com câncer, ao avaliar sua compreensão sobre a comunicação com a equipe médica e a equipe multiprofissional, bem como o seu interesse pelas informações sobre a sua doença/tratamento. Acredita-se que tais informações podem subsidiar futuramente a tomada de decisão da equipe médica para revelar um diagnóstico/ prognóstico ao principal interessado nas questões sobre a própria vida - o usuário - apesar dos pedidos das famílias pelo pacto de silêncio.

O presente estudo teve como objetivos: conhecer e analisar a visão da pessoa com câncer, em tratamento, sobre a comunicação em saúde; identificar as principais dificuldades do usuário no processo de comunicação com a equipe de saúde; identificar se os usuários querem ser informados sobre a doença oncológica e as opções de tratamentos; verificar se os usuários desejam que a família seja comunicada sobre a doença e o tratamento e; propor ações que aprimorem a qualidade da comunicação em saúde na atenção oncológica.

\section{MATERIAIS E MÉTODOS}

Delineou-se um estudo exploratório e descritivo, com abordagem qualitativa, previamente autorizado pelo Comitê de Ética em Pesquisa da Faculdade de Ciências da Saúde da Universidade de Brasília, sob o n 365.966/13. A primeira etapa envolveu a revisão da literatura, que subsidiou a elaboração do roteiro de entrevista semiestruturada aplicado na segunda etapa. O estudo foi realizado com usuários em tratamento oncológico em um Centro de Tratamento Especializado em Oncologia de um Hospital Universitário, entre agosto a dezembro de 2013.

Participaram do estudo dez usuários em tratamento oncológico convidados a integrar a pesquisa por se enquadrarem nos critério de inclusão. Para serem elegíveis para a pesquisa, estabeleceram-se como critérios de inclusão: idade igual ou superior a 18 anos; estar em acompanhamento no serviço no mínimo há um mês; conhecer o diagnóstico; ser alfabetizado; ter capacidade auditiva preservada, sem comprometimento cognitivo; aceitar participar da pesquisa e assinar ao Termo de Consentimento Livre e Esclarecido. O critério de exclusão foi ter recebido atendimento psicológico da pesquisadora anterior à realização da pesquisa. A seleção foi por conveniência e obedeceu a uma sequência temporal quanto ao tempo de ingresso no serviço, isto é, o participante deveria ter no mínimo um mês de admissão. Convencionou esse período por o usuário levar em média um mês para iniciar o tratamento oncológico - quimioterapia e/ou radioterapia - e, consequentemente, ter o mínimo de informação sobre a sua situação atual de saúde. Os participantes serão denominados com a letra " $\mathrm{P}$ " associado a um algarismo arábico, que representa cada um dos sujeitos entrevistados.

Os instrumentos utilizados foram: A) Linha do tempo: consiste numa técnica em que se orienta o participante a traçar uma linha que tem como início algum evento importante $^{27}$. É muito utilizada em psicoterapia e tem como objetivo resgatar o sujeito na sua história. No presente trabalho, o eixo principal foi o processo de comunicação em saúde desde a investigação diagnóstica da doença oncológica até o momento atual do seu tratamento. B) Roteiro de entrevista semiestruturada: busca inicialmente levantar os dados sociodemográficos - sexo, idade, estado civil, escolaridade, situação profissional - junto ao participante, e dados médico-clínicos - tipo de câncer, estadiamento e tempo desde o diagnóstico - nos registros em prontuários. Foi construído para esta pesquisa e embasou-se no levantamento da literatura sobre comunicação em saúde e autonomia do usuário. Os principais eixos investigados foram a qualidade da comunicação em saúde pela ótica do usuário; o interesse na informação sobre o processo de adoecimento e a participação nas decisões terapêuticas; o interesse de que a informação seja transmitida também a família e; quais as sugestões para a melhora da comunicação com a equipe de saúde e no serviço.

As entrevistas foram gravadas com o consentimento dos participantes. Posteriormente, degravadas na modalidade de transcrição in verbatim. Em seguida, submetidas à análise de conteúdo conforme Bardin ${ }^{28}$, com o objetivo de agrupar os relatos em categorias temáticas.

\section{RESULTADOS E DISCUSSÃO}

Participaram da entrevista dez sujeitos, dos quais seis eram do sexo feminino. A idade média dos entrevistados foi de 49 anos e variou de 31 a 67 anos. A escolaridade variou do ensino fundamental incompleto ao superior completo, com prevalência do ensino médio completo $(n=6)$. Quanto ao estadiamento clínico, houve a preponderância de pessoas com doença avançada $(n=7)$, caracterizada por tumores nos estádios III e IV de diferentes tipos de câncer. A Tabela 1 apresenta os dados sociodemográficos e médicoclínicos. 
Tabela 1. Dados sociodemográficos e médico-clínicos dos participantes.

\begin{tabular}{|c|c|c|}
\hline & Variável & $\begin{array}{c}\text { Amostra } \\
(n=10)\end{array}$ \\
\hline \multirow[t]{2}{*}{ Gênero } & Feminino & 6 \\
\hline & Masculino & 4 \\
\hline \multirow[t]{3}{*}{ Estado Civil } & Solteiro(a) & 2 \\
\hline & União consensual/casado(a) & 6 \\
\hline & Divorciado(a)/separado(a) & 2 \\
\hline \multirow[t]{3}{*}{ Escolaridade } & Ensino Fundamental Incompleto & 3 \\
\hline & Ensino Médio Completo & 6 \\
\hline & Ensino Superior Completo & 1 \\
\hline \multirow[t]{3}{*}{ Situação Profissional } & Desempregado(a) & 3 \\
\hline & Licença médica & 4 \\
\hline & Aposentado(a) & 3 \\
\hline \multirow[t]{7}{*}{ Tipo de câncer } & Colo do útero & 2 \\
\hline & Pulmão & 2 \\
\hline & Timoma & 1 \\
\hline & Esôfago & 1 \\
\hline & Mama & 2 \\
\hline & Melanoma & 1 \\
\hline & Basocelular & 1 \\
\hline \multirow[t]{4}{*}{ Estadiamento } & II & 2 \\
\hline & III & 2 \\
\hline & IV & 5 \\
\hline & Sem dados & 1 \\
\hline \multirow[t]{3}{*}{ Tempo de diagnóstico } & Até 1 ano & 6 \\
\hline & Mais de 1 ano & 3 \\
\hline & Mais de 5 anos & 1 \\
\hline
\end{tabular}

\section{Categoria 1 - A importância de saber sobre a doença}

Incluem os relatos referentes às transformações geradas pela descoberta de uma doença que ameaça a vida, os sentimentos desencadeados, as mudanças geradas na forma de encarar a existência humana e a forma como o médico o comunicou, o que pode facilitar ou dificultar o enfrentamento da situação. A revelação do diagnóstico foi declarada como o evento mais marcante na vida dos entrevistados $(n=10)$.

A maneira como se transmite a informação é tão importante quanto o seu conteúdo. Alguns estudiosos brasileiros $^{21}$ assinalam que o dilema não circunscreve a revelar ou não a verdade, e sim como fazê-lo. A despeito do impacto gerado pelo diagnóstico do câncer, a informação ajuda os sujeitos a enfrentarem essa realidade e preparar-se para os desafios futuros. A falta de informação possibilita abrir espaço para a fantasia, os pensamentos catastróficos e as expectativas irrealistas, que podem ser mais cruéis do que a própria informação omitida.
"Eles [médicos] quase não querem falar, né. Parece que quer esconder. Ah, pode falar a verdade. Pode ser claro, tem medo disso aí não. Eles falam CA, CA, CA. Eu já sabia disso. Tava pronto mesmo." [P4, sexo masculino, 65 anos]

"Ela [médica] foi assim: não vou esconder, vou falar diretamente. Só que eu senti tão aliviada, porque ela falou. Eu imaginei chegar lá e tirar o peito fora. Mas ela falou que não, que era um problema de câncer, que nós vamos fazer o tratamento." [P5, sexo feminino, 44 anos]

\section{Categoria 2 - Acesso aos serviços de saúde}

Abrange as verbalizações referentes à busca para garantir o tratamento para a pessoa com câncer, os caminhos encontrados pelos usuários para conseguir o direito de receber atendimento na rede pública de saúde e a ansiedade que a espera pela terapêutica gera nos mesmos.

A admissão em um serviço especializado em câncer $(n=4)$ e o início do tratamento quimioterápico $(n=4)$ configuram-se como o segundo e o terceiro evento mais importantes para os usuários. Os usuários que declararam a admissão como um episódio marcante encontraram dificuldades para garantir o acesso ao tratamento oncológico em um serviço de saúde pública.

"O mais importante foi quando eu consegui entrar aqui no Hospital, porque tava muito difícil. Na época, não tinha chance pra mim. Tava difícil! Teve pessoas importantes que tentaram e não conseguiram. Ai de repente surgiu 30 vagas e me encaixaram numa dessas." [P6, sexo masculino, 55 anos]

A dificuldade de acesso aos serviços de saúde é uma realidade que os usuários enfrentam no Brasil, nos diferentes níveis de assistência e em diversas regiões geográficas, o que torna a conquista desse direito um evento marcante para os sujeitos que recebem o diagnóstico de câncer. Assim, na luta pela vida, o caminho percorrido por alguns indivíduos é lançar mão de artifícios informais uma vez que o Estado não garantiu o direito à saúde. Apesar das legislações ${ }^{10,12}$ reafirmarem a universalidade do acesso à saúde, a realidade retrata duramente que o que resta para muitos indivíduos é recorrer pela via do "favor", "da ajuda", "da influência de pessoas importantes", que por sua vez reforçam o assistencialismo, a falta de autonomia do usuário e as práticas paternalistas da equipe de saúde.

"Na realidade eu consegui aqui graças a uma pessoa que trabalha aqui dentro. A gente sabe que tem gente pior do que na nossa situação, mas infelizmente é a lei da sobrevivência. Então assim, mesmo eu sabendo que tinha gente numa situação pior que a minha, eu 
tenho que sobreviver! Eu tenho filhos pra criar, então, eu tenho que passar na frente de quem for." [P1, sexo feminino, 31 anos]

Vale ressaltar que desde 2013 entrou em vigor a Lei no 12.732/2012 ${ }^{29}$ que busca garantir o atendimento no Sistema Único de Saúde às pessoas com neoplasia, no prazo máximo de 60 dias a partir da confirmação diagnóstica. O acesso ao tratamento é apontado na literatura como uma variável mediadora da adaptação ao contexto de adoecimento. Estudo com mulheres com câncer de mama ressaltaram a existência de fatores facilitadores para a adaptação psicossocial, entre eles a coesão e o apoio familiar, a percepção de fácil acesso aos serviços de saúde, a qualidade do atendimento e o apoio efetivo dos profissionais de saúde ${ }^{30}$. A adaptação não depende exclusivamente dos recursos que o indivíduo dispõe. Papel importante desempenha o Estado ao oferecer meios e condições para garantir o acesso rápido à terapêutica de uma doença que ameaça a vida, e no qual o tempo é um fator que prejudica a eficácia do tratamento.

\section{Categoria 3 - Interesse em saber sobre a doença e participar do tratamento}

Retrata se os indivíduos querem conhecer a verdade sobre a sua enfermidade e participar das decisões terapêuticas, bem como de que maneira querem estar envolvidos em tais escolhas. A maioria dos participantes $(n=8)$ destacaram querer receber informações sobre a doença, mesmo que sejam más notícias. Em relação ao envolvimento nas decisões terapêuticas, os sujeitos não se veem como capazes de decidir juntamente com o médico $(n=9)$. Delegam todas as decisões a equipe médica e indicam que a transmissão de informações é suficiente.

\footnotetext{
"Quero saber de tudo. Quero saber o que vai acontecer, como vai ser, o depois, o antes. O que for o melhor pra mim, ele [médico] sabe o que é o melhor para mim. Ele que decide, ele que é o médico, ele que sabe o que é o bom pra gente. Porque tem muita gente ignorante." [P7, sexo feminino, 43 anos]
}

De modo geral, os participantes apresentaram dificuldades quanto a sua capacidade de envolver-se nas decisões terapêuticas. Não se consideram aptos a decidir juntamente com o médico, pois só esse que detém conhecimento técnico e especializado, e assim delegam-no a responsabilidade na tomada de decisão. Alguns estudiosos constataram que idade avançada e baixa escolaridade são preditores de um papel passivo ${ }^{31}$. Porém, não é o que se observa nesta pesquisa, uma vez que os dados socio- demográficos indicam escolaridade elevada e faixa etária de meia-idade, sendo apenas três sujeitos acima de 60 anos de idade, e mesmo com essas características denotaram dificuldades em desempenhar papéis ativo no envolvimento das decisões. Entre as possíveis razões para as dificuldades de engajar-se em um papel ativo estão à vulnerabilidade diante do adoecimento, o que contribui para os sentimentos de invalidez e impotência ${ }^{32}$, que por sua vez podem promover a sensação de incapacidade em decidir sobre a terapêutica, ou enquanto estratégia utilizada pelo usuário para conseguir o acesso aos serviços de saúde.

\begin{abstract}
"Quero ouvir mais nada não. Já sei que tem. A única coisa se você curar é melhor, mas não cura. Eu sei disso. Fica só protelando a vida. [...] De mim não sai decisão nenhuma. Vim aqui pra ser tratado. Tô sendo tratado e é isso aí que eu quero. Se decidir se eu vou fazer a quimio, se vou fazer a radio, quem decide é o médico. A profissão dele é esse aí." [P4, sexo masculino, 65 anos]
\end{abstract}

Os próprios profissionais de saúde também podem fomentar essa vulnerabilidade ao não propiciar condições para que o usuário ocupe o lugar de direito, isto é, de sujeito na produção de saúde, e acabam por reforçar a passividade na implicação do cuidado com a saúde e o tratamento, em virtude das influências geradas pelo modelo biomédico que propõe uma entrega do sujeito para ser governado pelo médico ${ }^{14}$. Se os profissionais não são capacitados em sua formação acadêmica, como poderão favorecer a implicação ativa do usuário? Além das atitudes da equipe, o espaço físico pode ser desfavorável à escuta e o acolhimento, que por sua vez retroalimentam a postura do profissional e reforça a hierarquia de papéis. Soma-se também a essa problemática, o não conhecimento acerca dos seus direitos pelos usuários, conforme aponta estudo brasileiro $^{32}$ ao investigar os conhecimentos das pessoas com câncer sobre tais direitos. Declara que 45\% da amostra desconheciam-nos.

\section{Categoria 4 - Participação da família no tratamento}

Busca identificar se os sujeitos desejam que as informações sobre a sua doença sejam transmitidas também a família e como gostaria que esses estivessem envolvidos. A maioria $(n=9)$ manifestou interesse na participação familiar.

"Dentro do que for possível, tudo. Acho que com relação a informação para o paciente e para família, eu não vejo por que não informar. A decisão final sempre é do paciente, por mais que a família esteja envolvida emocionalmente. Quem tá com a doença 
é quem sabe o que tá passando. Acho que você até já assistiu ao filme, até de câncer - uma prova de amor - retrata bem o que eu acho. Aquela menina, ela que é paciente e que tinha que dar a palavra final. $O$ paciente é que sabe se aguenta ou não o tranco." [P3, sexo masculino, 40 anos]

Embora a participação da família seja valorizada durante o tratamento oncológico, deve-se ter cautela quanto a quem transmitir informações. Os usuários apesar de indicarem ser favoráveis a participação familiar, não delegaram a responsabilidade das decisões sobre a sua doença aos seus entes. É antes compartilhar notícias e não decisões, para respeitar o direito à autonomia do sujeito com câncer sobre a doença e a própria vida. Contudo, não é o que se observa nos estudos com os profissionais médicos. Pesquisas que investigam a revelação da informação junto aos médicos aponta que a maioria desses profissionais revelam primeiro a informação para a família, que decidiria se deveria contar ou não ao enfermo ${ }^{19,33}$.

\section{"Tudo que o médico tiver que contar que conte pra mim primeiro. Que não chame acompanhante nenhum. Porque eu quero ser a primeira a saber da notícia. Mesmo que seja uma notícia ruim." [P2, sexo feminino, 35 anos]}

As repercussões geradas pelo adoecimento de câncer impõem mudanças na rotina e nos papéis sociais de toda a família. Atualmente, cunhou-se o termo unidade de cuidados $^{34}$ para representar o binômio usuário/família que deve ser alvo dos cuidados da equipe de saúde. Sabe-se que o apoio instrumental e emocional ofertado pela rede de suporte social poderá constituir-se como uma estratégia de enfrentamento que contribuirá para a adaptação psicossocial. Nesse sentido, a família deve ser objeto de cuidados e de intervenção da equipe de saúde, para manejar conflitos, adequar à oferta de suporte social e promover o ajustamento emocional desta unidade 4 .

Verifica-se que embora os entrevistados indiquem querer a participação da família, não se pode afirmar que está autorizada a decidir pelo usuário. É antes estar ao lado, apoiar e acompanhar nesta fase de vida, o que permite aos familiares terem ciência da situação do seu ente, de modo a preparar-se para as mudanças, mesmo que seja a perda do seu parente.

\section{Categoria 5 - Entraves à comunicação}

Traz as dificuldades encontradas no processo de comunicação com a equipe de saúde ao longo do adoecimento. Os empecilhos a uma comunicação efetiva podem ser percebidos de forma clara ou velada.
"Fui pedir a ele [médico] um relatório para levar até o INSS. Me respondeu mau respondido: eu não vou fazer, porque você não tem direito a nada não! Eu disse que legal! Não tinha outro jeito do senhor falar comigo? Eu tava querendo um documento para eu ver se tinha direito pelo menos durante o tratamento. Se eu tinha direito a um benefício." [P10, sexo masculino, 62 anos]

A maneira como ocorre a relação médico-equipeusuário pode tanto facilitar, quanto criar empecilhos para o indivíduo desempenhar um papel ativo no processo saúde-doença. Deve-se dar devida atenção à linguagem empregada durante a transmissão de informações, para evitar problemas de interpretação de comunicação. A linguagem precisa ser adaptada às características culturais e sociais da clientela e o quanto se deseja saber sobre a doença. É preciso estar atento às reações psicológicas geradas com a comunicação e avaliar o nível de compreensão das informações transmitidas ${ }^{35}$. As reações emocionais podem ser percebidas no comportamento não verbal do usuário, apesar do mesmo não indicar dificuldades durante a divulgação das informações. Estar atento a esse componente cria condições para estabelecer um canal de comunicação eficaz, individualizado e acolhedor.

Ao avaliar os entraves no processo de comunicação, os entrevistados tiveram dificuldades em apontá-los e logo buscavam elogiar e minimizar a situação. A dificuldade de acesso aos serviços de saúde faz com que a garantia de atendimento seja algo muito almejado e faz emergir sentimentos de gratidão nesse contexto, sendo difícil reconhecer e criticar o serviço. O fenômeno de desejabilidade social também favorece a minimização da insatisfação com a comunicação em saúde, uma vez que a pesquisadora integrava a equipe de cuidados oncológicos, ainda que não prestasse assistência direta aos entrevistados.

"Ele é muito responsável, ele é dez [enfermeiro]. Só que eu perguntava, porque eu nunca na vida tinha feito quimioterapia. Aí fazendo umas perguntinhas e ele: mas eu já falei! Mas eu notei que ele não gostou daquilo. Poderia ter me dado uma enrolada [riso]. Mas tudo bem! Ele continua 10. [...] Eu não vou perguntar mais, porque ele não gosta. Nunca mais perguntei nada pra ele." [P9, sexo feminino, 67 anos]

\section{Categoria 6 - Postura do profissional como facilitador da comunicação em saúde}

Envolve comportamentos do profissional que favorecem o acolhimento e o sentir-se cuidado, em qualquer momento do adoecimento, por meio da expressão de afeto, de preocupação e da co-responsabilização no processo saúdedoença. Bem como o respeito e a validação das opiniões dos 
usuários e a atenção aos aspectos psicológicos desencadeados pela enfermidade e pela informação transmitida.

"Na quimio, tinha vezes que na hora que ia aplicar, tinha vezes que é difícil achar a veia e quando achava minha veia, às vezes doía, ai elas falavam: vai doer um pouquinho. Sabe aquele carinho [...] A gente surpreende com as coisas que tem aqui. Tudo que você vai fazer tem uma reunião. Acho muito bom. Antes de fazer a quimio, a gente teve reunião com todos os médicos, os psicólogos. Passou por todos. Teve o acolhimento. Agora com a radio a mesma coisa." [P8, sexo feminino, 48 anos]

Estudiosos da área de comunicação em saúde ${ }^{36,37}$ indicam que uma comunicação eficaz proporciona ao usuário sentir-se cuidado e acompanhado; conhece os problemas físicos e pessoais do doente; oferece informações verdadeiras, de forma delicada e progressiva, segundo suas necessidades, para planejar seu futuro; ajudar a manter a sua esperança; valoriza e reforça o princípio da autonomia e; tornar mais direta e interativa a relação médico-pessoa enferma. Desta forma, facilita a relação profissional de saúde/usuário e pode ser encarada como um fármaco em si mesmo, para além da terapêutica prescrita. O profissional tem que ter disponibilidade para ir ao encontro do outro, de modo a escutar a necessidade do sujeito na sua singularidade, que pode ir além do sofrimento pela doença do corpo físico.

"[Médico] me explicou que não tem cura, que ia depender do meu enfrentamento. E tô enfrentando assim com fé em Deus, mas também tô consciente. Tem que se preparar. Olha, eu te confesso que eu fiquei angustiada. Assim, parece que aquela esperança caiu um pouco. Mas eu pensei, eu tenho que enfrentar a realidade." [P9, sexo feminino, 67 anos]

Existem mitos de que a revelação da verdade pode desencadear uma depressão em pessoas com câncer avançado, o que justificaria as omissões destas informações pelo princípio da beneficência e não maleficência. Porém, alguns autores que buscaram avaliar se o conhecimento da verdade leva ao desenvolvimento da depressão, concluem que essa premissa é falsa ${ }^{22,38}$. Na população brasileira, os resultados denotam que saber do diagnóstico se correlaciona inversamente com a presença de depressão ${ }^{39}$. No presente trabalho, os participantes não demonstraram presença de sintomas depressivos em decorrência da comunicação em saúde ou denotaram problemas na relação médico-usuário por receberem informações sobre a doença, mesmo que seja da impossibilidade curativa da sua enfermidade. Inclusive, há uma ressignificação da esperança que se torna mais adaptativa ao contexto de prognóstico reservado e permite a preparação e o contato com perspectiva de finitude da vida.

\section{CONSIDERAÇÕES FINAIS}

A revelação da verdade é esperada pela maioria dos participantes do estudo, mesmo que envolvam más notícias, o que indica interesse para serem incluídos no processo de comunicação sobre a doença e o tratamento. Informar ao usuário sobre sua enfermidade, desde que seja uma preferência dos mesmos, é respeitar a sua autonomia e propiciar condições para preparar-se para as demandas que irão surgir. De forma geral, verifica-se que os usuários do presente trabalho não foram diferentes dos estudos brasileiros e internacionais em relação à preferência pela divulgação da doença oncológica.

Ainda permanece o desafio para a equipe interdisciplinar propiciar condições para o exercício da autonomia dos usuários nos serviços de saúde e para promover uma comunicação eficaz. Para tal a PNH traz alguns dispositivos que favorecem a participação e autonomia dos sujeitos em seus projetos terapêuticos, em especial para os casos de doenças crônicas, uma vez que fomenta a construção de vínculos, valorizando o saber dos sujeitos. Defendem a ideia e implementação da clínica ampliada, acolhimento e projeto terapêutico singular.

Uma vez que esta pesquisa não avaliou a percepção dos profissionais de saúde sobre o processo de comunicação, o que permitiria uma análise integral da relação profissionalusuário e o conhecimento das dificuldades para informar sobre a doença, o prognóstico e para promover a participação do usuário na tomada de decisão, sugere-se que estudos futuros integre a equipe médica e, se possível, a equipe interdisciplinar que prestam assistência às pessoas com câncer e ampliem o estudo da subjetividade para o diálogo com outras categorias profissionais.

\section{REFERÊNCIAS}

1. Conselho Federal de Medicina. Resolução CFM no 1931/2009. Brasília (DF): CFM; 2009.

2. Primo W, Garrafa V. Análise ética da revelação do diagnóstico e tratamento em pacientes com câncer genital ou mamário. Rev Assoc Med Bras. 2010;56(4):397-402. http://dx.doi.org/10.1590/S010442302010000400010

3. Veit MT, Barros LHC. Intervenções em psico-oncologia em instituições. In: Carvalho VAD, Franco MHP, organizadores. Temas em Psico-Oncologia. São Paulo: Summus; 2008. p. 362-72.

4. Carvalho CS. A Necessária atenção à família do paciente oncológico. Rev. Bras. Cancerol. 2008;54(1):87-96.

5. Gomes $\mathrm{CH}$, Silva PV, Mota FF. Comunicação do diagnóstico de câncer: análise do comportamento médico. Rev. Bras. Cancerol. 2009;55(2):139-43.

6. Frawley $\mathrm{T}$, Begley $\mathrm{CM}$. Ethical issues in caring for people witii carotid artery rupture. Br J Nurs. 2006;15(2):100-3. http://dx.doi. org/10.12968/bjon.2006.15.2.20371 
7. Surbone A, Ritossa C, Spagnolo AG. Evolution of truth-telling attitudes and practices in Italy. Crit Rev Oncol Hematol. 2004;52(3):165-72. http://dx.doi.org/10.1016/j.critrevonc.2004.09.002

8. Gulinelli A, Aisawa R, Konno S, Morinada C, Costardi W, Antonio R, Dumarco R, Moino R, Katz M, Giavarotti S, Skarbnik A, Forcione C, Chiba T, Martins M. Desejo de informação e participação nas decisões terapêuticas em caso de doenças graves em pacientes atendidos em um hospital universitário. Rev Assoc Med Bras. 2004;50(1):41-7. http://dx.doi.org/10.1590/S0104-42302004000100033

9. Brasil. Ministério da Saúde. Secretaria-Executiva. Núcleo Técnico da Política Nacional de Humanização. Humaniza SUS: Política Nacional de Humanização: a humanização como eixo norteador das práticas de atenção e gestão em todas as instâncias do SUS. Brasília (DF): Ministério da Saúde; 2004.

10. Brasil. Lei 8.080, de 19 de setembro de 1990: dispõe sobre as condições para a promoção, proteção e recuperação da saúde, a organização e o funcionamento dos serviços correspondentes e dá outras providências. Brasília, DF. (Set 19, 1990).

11. Conselho Federal de Medicina. Resolução CFM no 1.995/2012. Brasília (DF): CFM; 2012.

12. Brasil. Ministério da Saúde. Carta dos direitos dos usuários da saúde. Brasília (DF): Ministério da Saúde; 2007.

13. Ramos $\mathrm{AP}$, Bortagarai $\mathrm{FM}$. A comunicação não-verbal na área da saúde. Rev CEFAC. 2012;14(1):164-70. http://dx.doi.org/10.1590/ S1516-18462011005000067

14. Capra F. O Ponto de mutação. São Paulo: Cultrix; 1982.

15. Deslandes SF, Mitre RMA. Processo comunicativo e humanização em saúde. Interface Comun Saúde Educ. 2009;13(Supl. 1):641-49. http://dx.doi.org/10.1590/S1414-32832009000500015

16. Rossi FR, Lima MA. Fundamentos para processos gerenciais na prática do cuidado. Rev Esc Enferm USP. 2005;39(4):460-8. http:// dx.doi.org/10.1590/S0080-62342005000400013

17. Whitney SN, McCullough LB. Physicians' silent decisions: because patient autonomy does not always come first. Am J Bioeth. 2007;7(7):33-8. http://dx.doi.org/10.1080/15265160701399735

18. Mo HN, Shin DW, Woo JH, Choi JY, Kang J, Baik YJ, Huh YR, Won $\mathrm{JH}$, Park $\mathrm{MH}$, Cho $\mathrm{SH}$. Is patient autonomy a critical determinant of quality of life in Korea? End-of-life decision making from the perspective of the patient. Palliat Med. 2012;26(3):222-31. http:// dx.doi.org/10.1177/0269216311405089

19. Trindade E, Azambuja L, Andrade J, Garrafa V. O médico frente ao diagnóstico e prognóstico de câncer avançado. Rev Assoc Med Bras. 2007;53(1):68-74. http://dx.doi.org/10.1590/S010442302007000100023

20. Albuquerque PD, Araújo LZS. Informação ao paciente com câncer: o olhar do oncologista. Rev Assoc Med Bras. 2011;57(2):144-52. http://dx.doi.org/10.1590/S0104-42302011000200010

21. Visentin A, Labronici L, Lenardt $\mathrm{MH}$. Autonomia do paciente idoso com câncer: o direito de saber o diagnóstico. Acta Paul Enferm. 2007;20(4):509-13. http://dx.doi.org/10.1590/S010321002007000400021

22. Beste J. Instilling hope and respecting patient autonomy: reconciling apparently conflicting duties. Bioethics. 2005;19(3):215-31. http:// dx.doi.org/10.1111/j.1467-8519.2005.00438.x

23. Fainzang S. Les malades atteints d'un cancer et l'information: un autre regard sur la question. Bull Cancer. 2007;94(3):313-5.
24. Guven T. Truth-telling in cancer: examining the cultural incompatibility argument in Turkey. Nurs Ethics. 2010;17(2):15966. http://dx.doi.org/10.1177/0969733009352046

25. Surbone A. Telling the truth to patients with cancer: what is the truth? Lancet Oncol. 2006;7(11):944-50. http://dx.doi.org/10.1016/ S1470-2045(06)70941-X

26. Arraras JI, Greimel E, Chie WC, Sezer O, Bergenmar M, Costantini A Young T, Vlasic KK, Velikova G. European Organisation for Research and Treatment of Cancer Quality of Life Group. Cross-cultural differences in information disclosure evaluated through the EORTC questionnaires. Psychooncology. 2013;22(2):268-75. http://dx.doi. org/10.1002/pon.2088

27. Brito DC. A orientação profissional como instrumento reabilitador de pacientes portadores de doenças crônicas e deficiências adquiridas. Psicol Rev. 2009;15(1):106-19.

28. Bardin L. Análise de conteúdo. Lisboa: Edições 70; 2009.

29. Brasil. Lei no 12.732, de 22 de novembro de 2012: dispõe sobre o primeiro tratamento de paciente com neoplasia maligna comprovada e estabelece prazo para seu início. Brasília, DF. (Nov 22, 2012).

30. Gimenez MGG, Queiroz E. As diferentes fases de enfrentamento durante o primeiro ano após a mastectomia. In: Gimenez MGG, organizadora. A mulher e o câncer. São Paulo: Editorial Psy II; 1997. p.173-96.

31. Brown VA, Parker PA, Furber L, Thomas AL.. Patient preferences for the delivery of bad news - the experience of a UK Cancer Centre. Eur J Cancer Care (Engl). 2011;20(1):56-61. http://dx.doi. org/10.1111/j.1365-2354.2009.01156.x

32. Sonobe HM, Buetto LS, Zago MMF. O conhecimento dos pacientes com câncer sobre seus direitos legais. Rev Esc Enferm USP. 2011;45(2):342-48. http://dx.doi.org/10.1590/S008062342011000200006

33. Mobeireek AF, Al-Kassimi F, Al-Zahrani K, Al-Shimemeri A, alDamegh S, Al-Amoudi O, Al-Eithan S, Al-Ghamdi B, Gamal-Eldin M. Information disclosure and decision-making: the Middle East versus the Far East and the West. J Med Ethics. 2008;34(4):225-9. http://dx.doi.org/10.1136/jme.2006.019638

34. Franco MH. Assistência a Unidade de Cuidados: paciente, família e equipe de cuidados. In: Congresso Brasileiro de Oncologia Clínica. Brasília (DF); 2013.

35. Coutinho SMG. Comunicação médico-paciente em oncohematologia pediátrica: efeitos de um procedimento de intervenção psicológica [dissertação]. Brasília (DF): Universidade de Brasília; 2013.

36. Braga EM, Silva MJP. Comunicação competente: visão de enfermeiros especialistas em comunicação. Acta Paul Enferm. 2007;20(4):41014. http://dx.doi.org/10.1590/S0103-21002007000400004

37. Perdicaris AAM, Silva MJP. A comunicação essencial em oncologia. In: Carvalho VAD, Franco MHP, organizadores. Temas em psicooncologia. São Paulo: Summus; 2008. p.403-13.

38. Dégi CL. Non-disclosure of cancer diagnosis: an examination of personal, medical, and psychosocial factors. Support Care Cancer. 2009;17(8):1101-7. http://dx.doi.org/10.1007/s00520-008-0568-0

39. Diniz RW, Gonçalves MS, Bensi CG. O conhecimento do diagnóstico de câncer não leva à depressão em pacientes sob cuidados paliativos. Rev Assoc Med Bras. 2006;52(5):298-03. http://dx.doi. org/10.1590/S0104-42302006000500014 